\title{
Regional Energy Integration - A System Modeling Approach
}

\author{
Hosam E. Emara-Shabaik, Gulnur Kalimuldina, and Sarim Al-Zubaidy
}

\begin{abstract}
Energy integration aims at achieving sustainable self-sufficiency among countries in a geographical region. The challenges of integrating the energy resources of a group of countries are addressed in this paper using a system modeling approach. As a starting point, the model accounts for the energy needs, production, and interactive cooperation between the countries in a region. Different case scenarios are simulated and their results are analyzed. The model shows that countries in a specific region can effectively manage their energy resources to the benefit of all and every country in the considered region.
\end{abstract}

Index Terms-Energy, regional integration, system modeling, energy integration.

\section{NOTATIONS}

$R_{i}$ - reserves of country $i$

$R_{j}$ - reserves of country $j$

$R_{m}$ - reserves of country $m$

$P_{i}$ - available production of country $i$

$P_{j}$-available production of country $j$

$P_{m}$ - available production of country $m$

$Q_{p i^{-}}$drilling production of country $i$

$Q_{p j}$ - drilling production of country $j$

$Q_{p m^{-}}$drilling production of country $m$

$Q_{c l}$ - consumption of country $i$

$Q_{c j}$ - consumption of country $j$

$Q_{c m}-$ consumption of country $m$

$k$-year

$N_{i-}$ factor of country i contributing to country $j$

$N S_{i m}$ - factor of country i contributing to country $m$

$N S_{j i}-$ factor of country $\mathrm{j}$ contributing to country $i$

$N S_{j m}$ - factor of country j contributing to country $m$

$N S_{m i}$ - factor of country m contributing to country $i$

$N S_{m j}$ - factor of country m contributing to country $j$

\section{INTRODUCTION}

Energy integration between countries provides a viable alternative to energy imports from other parts which might involve high availability risk or with high transportation cost. Therefore, the integration effort strives to achieve a sustainable energy sufficiency among the countries of a geographical region. A case in point is the energy demand and supply in Asia. It is projected that in the next 20 years the northeast Asia demand for energy will increase from 59

Manuscript received October 25, 2012; revised January 11, 2013.

Hosam E. Emara-Shabaik, Gulnur Kalimuldina, and Sarim Al-Zubaidy are with Nazarbayev University, Astana, Kazakhstan (e-mail: gkalimuldina@nu.edu.kz). to 78 percent [1], [2]. There is strong derive to shift the reliance of countries of the region from the Middle East oil to the immense energy resources in the Asia region such as Russia and Kazakhstan who can export abundant amount of oil and natural gas to neighboring countries. As an example, Russia and China intend to implement cooperation in pipelines and electricity transmission lines between them. According to Zobaa and Lee's work by 2020 it will give Russia an opportunity to supply half of Northeast Asia with natural gas [2]. This cooperation is a good example on how competitor countries can be integrated in order to solve global energy demand problems [3]. However, such regional integration in the energy field has its own difficulties. Security, political and leadership issues remain as sources of tension among the countries of the region which makes it desirable to build global energy market connections or energy flow nets. The energy globalization involves benefits to both customers and suppliers, however new political regulations and market reforms are required for effective implementation. More than fifth of the global energy consumption is in the Northeast Asia region and it is expected to reach one-third of world's energy need during the next 20 years [2]. Fig. 1 highlights the growth of China oil imports. It can be observed that the growth of import sustains a positive gradient during the period 1993-2007 [4]. Fig. 2 shows the dependency on oil imports in different regions of the world [5].

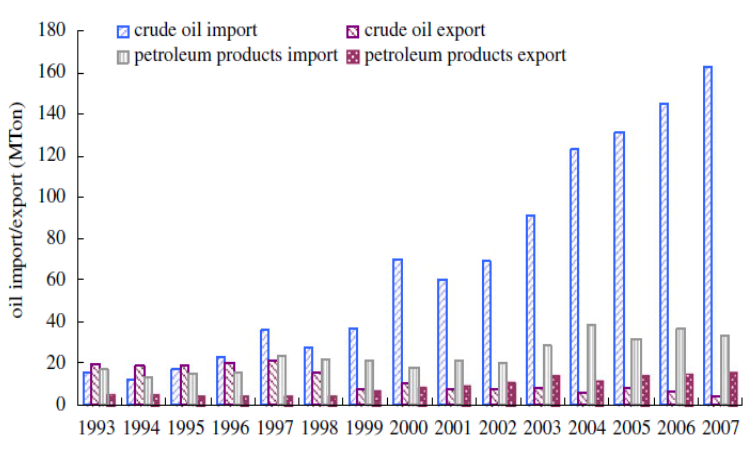

Fig. 1. China's oil imports and exports over the period 1993-2007.

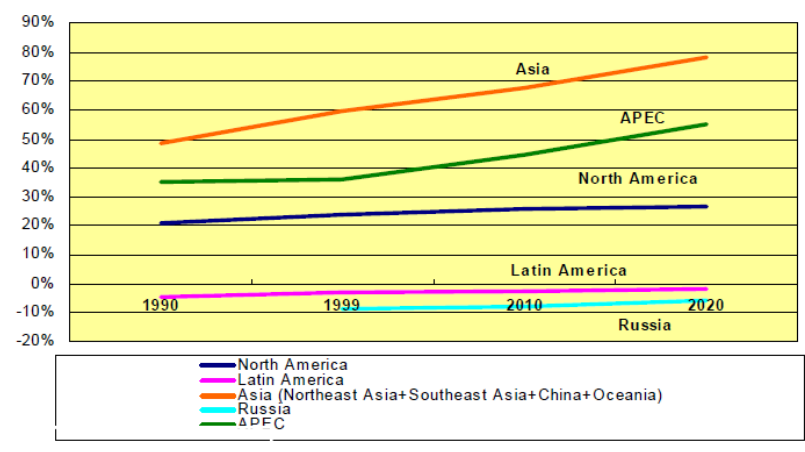

Fig. 2. Oil import dependency (1990-2020). 
Consequently more attention will have to be paid to the development of energy production in Asia. The high reliance of countries such as China, Japan and Korea on the Middle East oil can be transferred to the immense energy resources in Asia region. One of the rich suppliers in the region is Russia which can export abundant amounts of oil and natural gas to neighboring countries in Northeast Asia and the AsiaPacific rim. Relations among the countries of the region are still under tension due to the weakness of security frameworks, boarder disputes and political leadership. Even with undertaking risks countries in this region are attempting to start building strong global energy market connections. As an example, Russia and China intended to implement cooperation in pipelines and electricity transmission lines between them. According to Zobaa and Lee's work by 2020 it will give Russia an opportunity to supply half of Northeast Asia with natural gas. This cooperation is a good example how competitor countries can be interacted in order to solve global energy demand problems [3].

Apparently the available literature on energy modeling studies seems to be limited in scope. The majority of sources provide different types of data on availability, production and consumption of different forms of energy as mentioned above. On the modeling side the focus has been on the supply and demand analysis as coupled to econometric studies [6] and [7]. In [6], several types of models are described, e.g. Sectoral Models, Industrial Market Models, Energy System Models, and Integrated Energy Econometric Models. Sectoral models focus on market supply and demand for a specific energy source. Industrial market models are econometric type models geared for industry planning and expansion taking into effects energy regulatory policies. Demand forecast of all forms of energy are treated by the energy system models. Integrated energy econometric models provide the coupling between macroeconomic inputoutput models and process oriented models by providing demand level for industry planning purposes.

What seems to be lacking are models which can describe the dynamic interaction between producing and consuming countries in a region to serve as a basis to study various possible scenarios of cooperation among these countries in order to achieve self-sufficient secure energy supply in the region. This paper aims at filling in this gap

In this paper we will propose a system's modeling approach to address scenarios for energy integration among countries aiming at achieving regional energy sufficiency. We will consider the factors affecting such integration and the consequences it has on the oil production by those countries.

\section{THE INTEGRATION MODEL}

A dynamic model is developed which takes into consideration a number of key variables. The model is driven by the yearly production and consumption of each country as inputs. The states of the system are defined in terms of the yearly reserves in tonnes and production utilization in tonnes of each country in the region. While the inputs to the model account for the yearly drilling in tonnes and the yearly consumption in tonnes of each country. The intra-country trade levels are parameters of the model which can be varied and experimented with (particularly when relations change), in order to come up with an effective integration policy.

The interaction coefficient from country ' $i$ ' to country ' $j$ ' represents the percentage of the unfulfilled need of country ' $\mathrm{j}$ ' that country ' $\mathrm{i}$ ' is willing to provide. Mathematically, the model is given by equation (1), which represents the case of three countries energy integration.

$$
E x(k+1)=C x(k)+B u(k)
$$

where, the system state and input vectors and matrices are given as,

$$
\begin{aligned}
& x(k)=\left[R_{i}(k) R_{j}(k) R_{m}(k) P_{i}(k) P_{j}(k) P_{m}(k)\right]^{\prime} \\
& u(k)=\left[Q_{P i}(k) Q_{P j}(k) Q_{P m}(k) Q_{C i}(k) Q_{C j}(k) Q_{C m}(k)\right]^{\prime} \\
& E=\left[\begin{array}{cccccc}
1 & 0 & 0 & 0 & 0 & 0 \\
0 & 1 & 0 & 0 & 0 & 0 \\
0 & 0 & 1 & 0 & 0 & 0 \\
0 & 0 & 0 & \left(1+N_{j i}+N_{w i}\right) & -N_{i j} & -N_{i m} \\
0 & 0 & 0 & -N_{j i} & \left(1+N_{i j}+N_{m j}\right) & -N_{j m} \\
0 & 0 & 0 & -N_{m i} & -N_{m j} & 1+N_{i m}+N_{j m}
\end{array}\right] \\
& C=\left[\begin{array}{llllll}
1 & 0 & 0 & 0 & 0 & 0 \\
0 & 1 & 0 & 0 & 0 & 0 \\
0 & 0 & 1 & 0 & 0 & 0 \\
0 & 0 & 0 & 1 & 0 & 0 \\
0 & 0 & 0 & 0 & 1 & 0 \\
0 & 0 & 0 & 0 & 0 & 1
\end{array}\right]
\end{aligned}
$$$$
B=\left[\begin{array}{cccccc}
-1 & 0 & 0 & 0 & 0 & 0 \\
0 & -1 & 0 & 0 & 0 & 0 \\
0 & 0 & -1 & 0 & 0 & 0 \\
1 & 0 & 0 & \left(N_{j i}+N_{m i}-1\right) & -N_{i j} & -N_{i m} \\
0 & 1 & 0 & -N_{j i} & \left(N_{i j}+N_{m j}-1\right) & -N_{j m} \\
0 & 0 & 1 & -N_{m i} & -N_{m j} & \left(N_{i m}+N_{j m}-1\right)
\end{array}\right]
$$

Although the model is in a descriptor form it can be converted to a regular state space form as the right hand side matrix is nonsingular for non negative interaction parameters. Fig. 3shows the proven reserve, according to BP Statistical Review of World Energy 2012, of the three countries considered in this study, Russia, China and Kazakhstan [8]. Among the three Russia has the highest reserve, while China has the least reserves. Both Russia and Kazakhstan have the ability to contribute to China's oil needs.

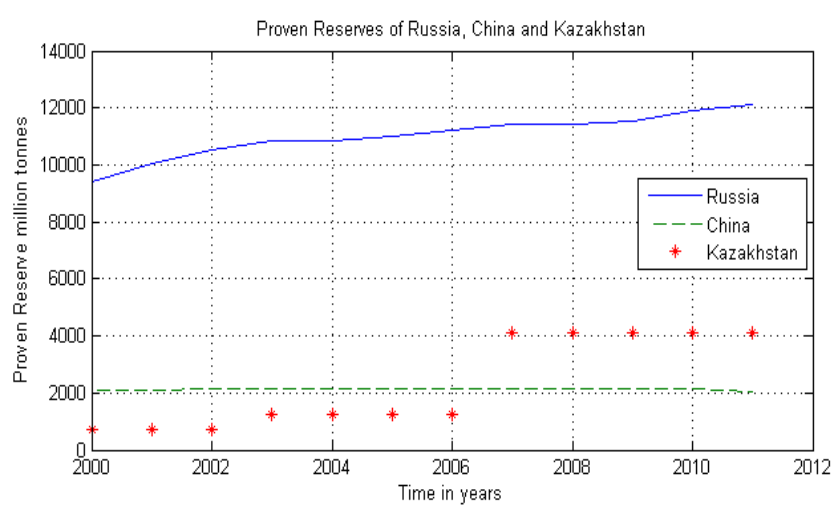

Fig. 3. Proven Reserves of Russia, China and Kazakhstan from BP Statistical Review of World Energy 2012. 


\section{RESULTS}

Three countries; Russia (referred to as country i), China (referred to as country $\mathrm{j}$ ) and Kazakhstan (referred to as country $\mathrm{m}$ ); are considered to illustrate the idea of intracountries interactions in order to achieve self sufficiency among them in the oil sector. Different interaction scenarios between the countries are considered. Case 1 considers the scenario represented by the interaction factors, $N S_{i j}=1$, $N S_{j i}=0, N S_{i m}=0, N S_{m i}=0, N S_{j m}=0, N S_{m j}=0$. Therefore, Country $\mathrm{i}$ (Russia) supplies country $\mathrm{j}$ (China) with all of its locally unfulfilled oil needs. In order to achieve this production of the three countries considered is as shown in Fig. 4.

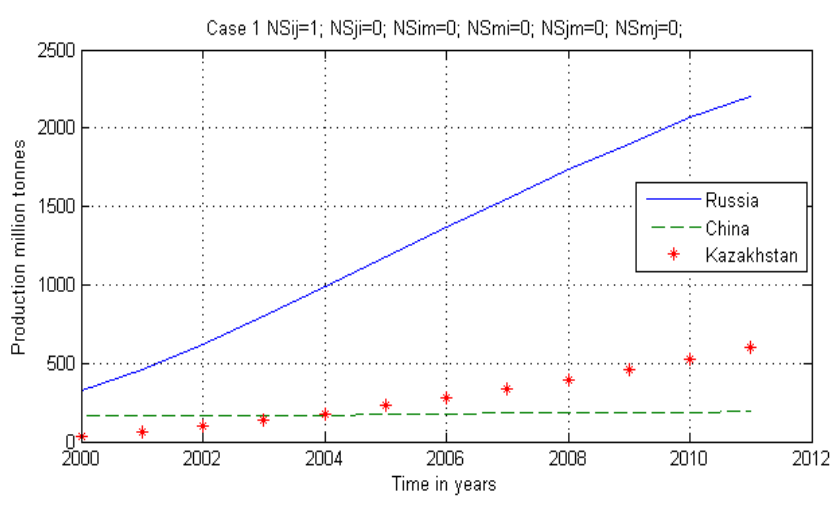

Fig. 4. Case 1 - Oil production, Russia fully supplies China's locally unfulfilled oil needs.

Case 2, both Russia and Kazakhstan are contributing to China's oil needs. This represented by the following interaction factors, $N S_{i j}=0.7, N S_{j i}=0, N S_{i m}=0, N S_{m i}=0, N S_{j m}=0$, $N S_{m j}=0.3$. The interaction happens between all three countries (but no oil export from China), however Russia provides more oil $(\mathrm{NS}=0.7)$ rather than Kazakhstan $(\mathrm{NS}=0.3)$

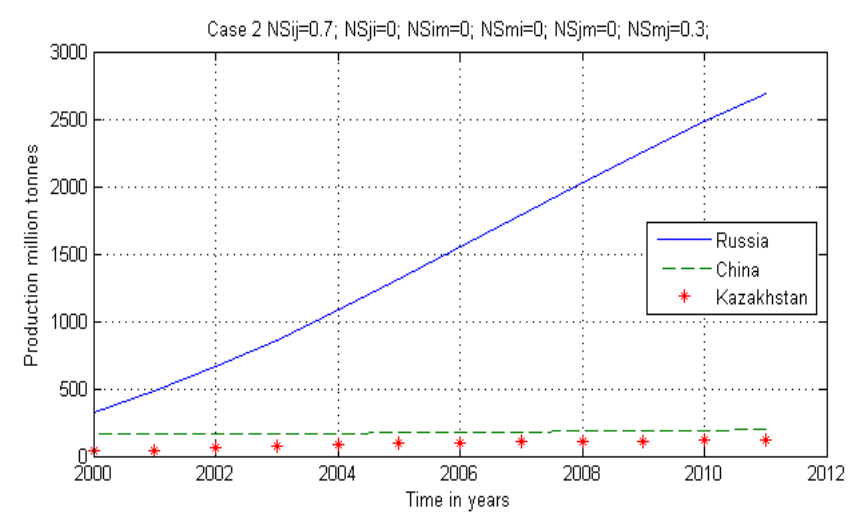

Fig. 5. Case 2 - Oil production, Russia supplies (70\%) and Kazakhstan supplies $(30 \%)$ of China's locally unfulfilled oil needs.

Case 3, both Russia and Kazakhstan are equally providing the oil needs of China. This is represented by the interaction factors given by, $N S_{i j}=0.5, N S_{j i}=0, N S_{i m}=0, N S_{m i}=0, N S_{j m}=0$, $N S_{m j}=0.5$

Case 4, Russia supplies 30\% while Kazakhstan supplies $70 \%$ of China's oil needs $N S_{i j}=0.3, N S_{j i}=0, N S_{i m}=0, N S_{m i}=0$, $N S_{j m}=0, N S_{m j}=0.7$

Case 5 Only Kazakhstan is fully providing oil to China. This scenario is represented by the interaction factors given by $N S_{i j}=0, N S_{j i}=0, N S_{i m}=0, N S_{m i}=0, N S_{j m}=0, N S_{m j}=1$.

Comments and discussions on the different cases are given in the following section.

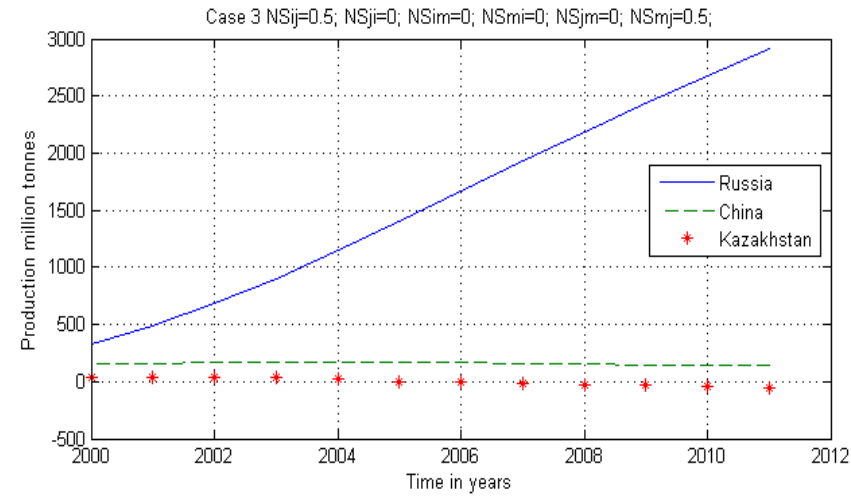

Fig. 6. Case 3 - Oil production, Russia and Kazakhstan equally supplying China's locally unfulfilled oil needs.

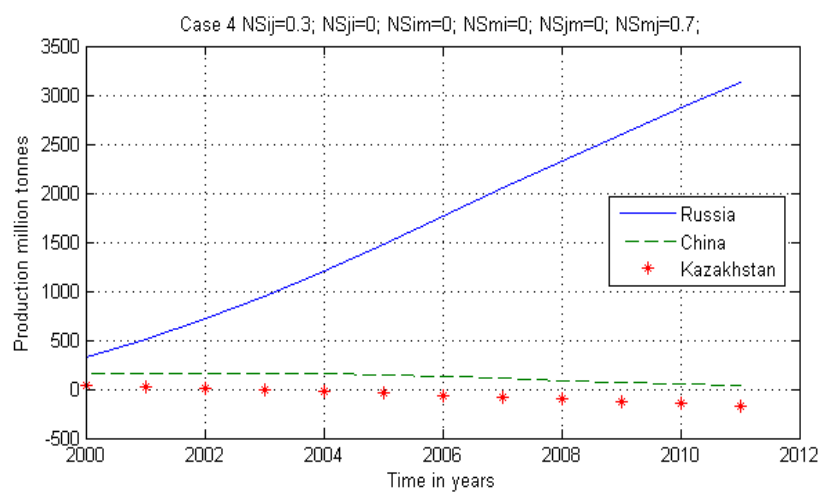

Fig. 7. Case 4 - Oil production, Russia supplies (30\%) and Kazakhstan supplies $(70 \%)$ of China's locally unfulfilled oil needs.

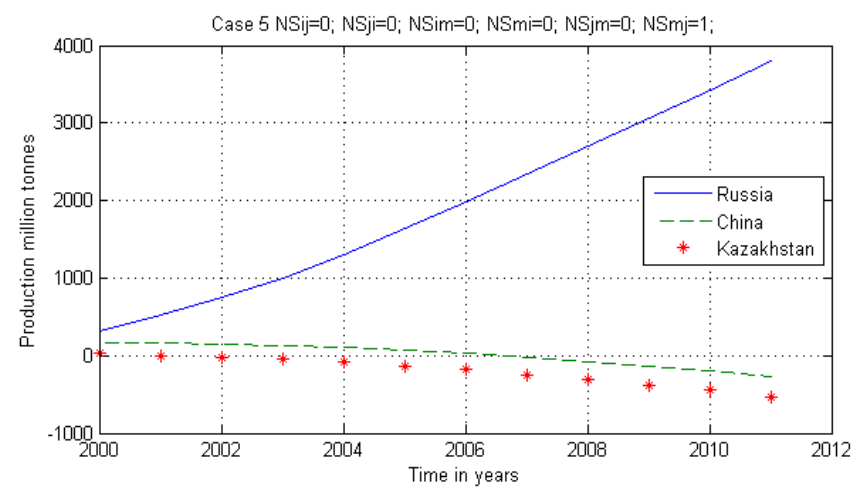

Fig. 8. Case 5 - Oil production, Kazakhstan fully supplies China's locally unfulfilled oil needs.

\section{DISCUSSION}

In the Fig. 4 it is shown that Russia is able to provide oil drilling to fulfill its own needs and also effectively supply oil to fulfill oil need of China. This is a possible sustainable interaction. The Fig. 5 illustrates that all countries are fulfilled and above zero. However Kazakhstan showed significant decrease on its drilling capabilities to satisfy its own needs. Therefore, this is still a possible sustainable interaction. It is clear from the Fig. 6 that Kazakhstan supplied more than it can provide to China. In the result drilling production of Kazakhstan goes to the minus. Since Kazakhstan is unable to supply China to fulfill its consumption, both counties go to the below zero results as it is demonstrated in the Fig. 7. Fig. 8 shows that Kazakhstan 
and China are going down on their production trends. It is the result of that Kazakhstan cannot provide China with required oil to fulfill its consumption needs. Therefore, the last three scenarios are not sustainable scenarios.

\section{CONCLUSION}

This paper provides a paradigm to analyze possible integration policy among a group of countries in order to achieve self-sufficiency/reduced reliance on outside sources in the oil energy sector. The levels of interaction/cooperation among these countries as well as the drilling policy of each individual country in order to achieve the goals of integration are the decision variables in this case. A feedback policy can be devised in terms of these decision variables as function of oil availability levels of the countries in the group. This is the next effort of our research in this area. Such policies will take into consideration the stability of the intra-country integration dynamics.

The methodology adopted here can be easily extended to achieve integration among countries in other energy sectorsin a similar way.

\section{REFERENCES}

[1] Y. Jung, Energy Security in Asia: Providing for Current and Future Energy Needs, vol. 6, pp.133-144, 2003.

[2] A. F. Zobaa and W. J. Lee, The globalization of Energy Markets in Asia, IEEE, 2006.

[3] N. Luong, R. Wahnschafft, F. Zhou, S. Abe, G. Saneev, T. Sukhbaatar, and S. Yul Shim, "North-East Asia: Perspectives for Inter-Country Cooperation in Energy Sector Development," pp.105-132, 2003.

[4] G. Wu, L. C. Liu, Y. M. Wei, "Comparison of China's oil import risk: Results based on portfolio theory and a diversification index approach," Energy Policy, vol. 37, pp. 3557-3565, 2009.
[5] APERC, APEC Energy Demand and Supply Outlook: 2002, Asia Pacific Energy Research Centre, Tokyo, 2002.

[6] K. C. Hoffman and D. O. Wood, "Energy system modeling and forecasting," MIT Energy Lab, 75-013 WP, 1975.

[7] J. P. Charpentier, "A review on energy model," No. RR·74-iO, Luxemburg, Austria: Inst. Appl. Syst. Anal., July1974.

[8] BP Statistical Review of World Energy, (June 2012). [Online]. Available:

http://www.bp.com/sectionbodycopy.do?categoryId=7500\&contentId $=7068481$.

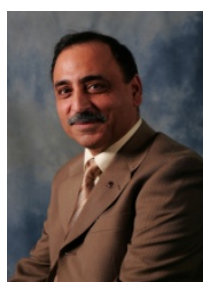

Hosam E. Emara-Shabaik is a professor of Mechanical Engineering at Nazarbayev University, Astana, Kazakhstan. His area of specialty is Systems Theory, Control and Estimation. He has numerous publications dealing with dynamic systems modeling, identification, estimation and control.

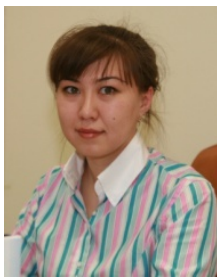

Gulnur Kalimuldina received her MSc from The University of Manchester, Manchester, the UK, 2011 and bachelor degree from Kazakh-British Technical University, Kazakhstan, 2010. Her current position is a teaching assistant at Nazarbayev University in Kazakhstan. Current research interests in the field of energy integration modeling and rechargeable lithium battery systems.

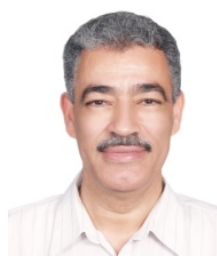

Sarim Al-Zubaidy is Vice-Dean (Teaching Learning) at the School of Engineering, Nazarbayev University, Kazakhstan. He has over thirty year experience in both senior academic and admistrative positions in a avriety of higher education institutions around the world. He has authored over 100 peer reviewed articles and trechnical papers. His expertise ranges drom traditional to newly formed universties to those in transtion. 